 \\ Insights from two decades of the Student Conference on Conservation \\ Science \\ Geldmann, Jonas; Ales-Pinto, Helena; Amano, Tatsuya ; Bartlett, Harriet; \\ Christie, Alec P. ; Collas, Lydia ; Cooke, Sophia C. ; Correa, Roberto ; Cripps, \\ Imogen ; Doherty, Anya ; Finch, Tom ; Garnett, Emma E. ; Hua, Fangyuan ; \\ Jones, J.P.G.; Kasoar, Tim; MacFarlane, Douglas ; Martin, Philip A.; Mukherjee, \\ Nibedita ; Mumby, Hannah S. ; Payne, Charlotte ; Petrovan, Silviu O. ; Rocha, \\ Ricardo ; Russell, Kirsten ; Simmons, Benno I. ; Wauchope, Hannah S. ; \\ Worthington, Thomas A. ; Trevelyan, Rosie ; Green, Rhys ; Balmford, Andrew

\section{Biological Conservation} \\ DOI: \\ 10.1016/j.biocon.2020.108478
}

Published: 01/03/2020

Peer reviewed version

Cyswllt i'r cyhoeddiad / Link to publication

Dyfyniad o'r fersiwn a gyhoeddwyd / Citation for published version (APA):

Geldmann, J., Ales-Pinto, H., Amano, T., Bartlett, H., Christie, A. P., Collas, L., Cooke, S. C., Correa, R., Cripps, I., Doherty, A., Finch, T., Garnett, E. E., Hua, F., Jones, J. P. G., Kasoar, T., MacFarlane, D., Martin, P. A., Mukherjee, N., Mumby, H. S., ... Balmford, A. (2020). Insights from two decades of the Student Conference on Conservation Science. Biological Conservation, 243, [108478]. https://doi.org/10.1016/j.biocon.2020.108478

Hawliau Cyffredinol / General rights

Copyright and moral rights for the publications made accessible in the public portal are retained by the authors and/or other copyright owners and it is a condition of accessing publications that users recognise and abide by the legal requirements associated with these rights.

- Users may download and print one copy of any publication from the public portal for the purpose of private study or research.

- You may not further distribute the material or use it for any profit-making activity or commercial gain

- You may freely distribute the URL identifying the publication in the public portal ? 
Authors: Jonas Geldmann ${ }^{1,2}$, Helena Alves-Pinto ${ }^{3,4,1}$, Tatsuya Amano ${ }^{5,1,6}$, Harriet Bartlett ${ }^{1,7}$, Alec P. Christie $^{1}$, Lydia Collas ${ }^{1}$, Sophia C. Cooke ${ }^{1}$, Roberto Correa ${ }^{1}$, Imogen Cripps ${ }^{1}$, Anya Doherty ${ }^{1}$, Tom Finch $^{8}$, Emma E. Garnett ${ }^{1}$, Fangyuan Hua ${ }^{9,1}$, Julia Patricia Gordon Jones ${ }^{10}$, Tim Kasoar ${ }^{1}$, Douglas MacFarlane ${ }^{1,11}$, Philip A Martin ${ }^{1,12}$, Nibedita Mukherjee ${ }^{1}$, Hannah S. Mumby ${ }^{1,13}$, Charlotte Payne ${ }^{1}$, Silviu O. Petrovan ${ }^{1}$, Ricardo Rocha, ${ }^{1,14}$, Kirsten Russell ${ }^{1}$, Benno I. Simmons ${ }^{1,15,16}$, Hannah S. Wauchope $^{1}$, Thomas A. Worthington ${ }^{1}$, Rosie Trevelyan ${ }^{17}$, Rhys Green ${ }^{1,8}$, and Andrew Balmford ${ }^{1}$

Affiliations:

1 Conservation Science Group, Department of Zoology, University of Cambridge, Downing St., Cambridge CB2 3EJ, UK

2 Center for Macroecology, Evolution and Climate, Natural History Museum of Denmark, University of Copenhagen, Universitetsparken 15, 2100, Copenhagen E, Denmark.

3 Programa de Pós Graduação em Ecologia, Universidade Federal do Rio de Janeiro, CEP 21941-590 Rio de Janeiro, Brazil

4 Rio Conservation and Sustainability Science Centre, Department of Geography and the Environment, Pontifícia Universidade Católica, Rio de Janeiro 22453-900, Brazil

5 School of Biological Sciences, University of Queensland, Brisbane, 4072 Queensland, Australia

6 Centre for the Study of Existential Risk, University of Cambridge, 16 Mill Lane, Cambridge, CB2 $1 \mathrm{SB}, \mathrm{UK}$

7 Department of Veterinary Medicine, University of Cambridge, Madingley Road, Cambridge, CB3 $0 \mathrm{ES}, \mathrm{UK}$

8 RSPB Centre for Conservation Science, RSPB, The Lodge, Sandy, SG19 2DL, United Kingdom

9 Institute of Ecology, Peking University, Haidian Road, Beijing 100871, China

10 College of Environmental Sciences and Engineering, Bangor University, LL57 2UW, UK

11 School of Psychological Science, University of Western Australia, 35 Stirling Hwy, Crawley WA 6009, Australia

12 BioRISC, St. Catharine's College, Cambridge CB2 1RL, UK.

13 School of Biological Sciences, Kadoorie Biological Sciences Building, University of Hong Kong, Pok Fu Lam Road, Hong Kong SAR

14 "CIBIO-InBIO, Research Centre in Biodiversity and Genetic Resources, University of Porto, Vairão, Portugal

15 Department of Animal and Plant Sciences, University of Sheffield, Western Bank, Sheffield, S10 2TN, United Kingdom

16 Centre for Ecology and Conservation, College of Life and Environmental Sciences, University of Exeter, Penryn, UK

17 Tropical Biology Association, Cambridge, UK

\section{Abstract}

Conservation science is a crisis-oriented discipline focused on reducing human impacts on nature. To explore how the field has changed over the past two decades, we analyzed 3,245 applications for oral presentations submitted to the Student Conference on Conservation Science (SCCS) in Cambridge, UK. SCCS has been running every year since 2000 , aims for global representation by providing bursaries to early-career conservationists from lower-income countries, and has never had a thematic focus, beyond conservation in the broadest sense. We found that the majority of projects submitted to SCCS were based on primary biological data collected from local scale field studies in the tropics, contrary to established literature which highlights gaps in tropical research. Our results showed a small increase 
over time in submissions framed around how nature benefits people as well as a small increase in submissions integrating social science. Our findings suggest that students and early-career conservationists could provide pathways to increase availability of data from the tropics and address well-known biases in the published literature towards wealthier countries. We hope this research will motivate efforts to support student projects, ensuring data and results are published and data made publicly available.

Keywords: Bias; Capacity building; Cross-disciplinarity; Early career; Field study; New conservation; Student

\section{Introduction}

Conservation science focuses on understanding and reducing the negative impacts of human activities on nature, and has, from its inception, been framed as a "mission-oriented discipline" (Soulé 1985). It has its origins in biology and, as a result, its initial emphasis was on describing and explaining the distribution of biodiversity as well as the ecological and evolutionary processes shaping the diversity of life under human pressure. However, over the last few decades it has become increasingly clear that understanding biological processes alone is insufficient in identifying robust solutions to reduce pressures on nature and the environment (Balmford and Cowling 2006; Bennett et al. 2017; Kareiva and Marvier 2012; Meine et al. 2006). This has led to the integration of the social sciences, economics, and psychology to understand the role of people when addressing conservation problems (Mace 2014; Martin et al. 2012b; Teel et al. 2018) and an interest in the motivations for conserving nature (Greenwald et al. 2013; Kareiva 2014; Kareiva and Marvier 2012; Noss et al. 2013; Soule 2013).

Even though primary data are the foundation for conservation science and management (Tewksbury et al. 2014; Wilson 2017), the proportion of published studies based on primary data collection has decreased over the past two decades, though they still represent $70 \%$ of ecological studies (Ríos-Saldaña et al. 2018). In addition, the conservation literature continues to exhibit considerable geographical bias toward wealthier, often English-speaking countries (Amano and Sutherland 2013; Martin et al. 2012a) and certain taxonomic groups (Clark and May 2002) and away from the tropics (Collen et al. 2008; Mammides et al. 2016; Meijaard et al. 2015). These biases limit our ability to assess what conservation actions work and where.

Analysis of trends in peer-reviewed articles can give an unrepresentative picture of the work being done on the ground (Godet and Devictor 2018). Understanding the extent to which the peer-reviewed literature is missing specific types of studies or research from certain parts of the world can help to highlight publications gaps and improve the uptake of data and experiences outside the Western dominated academic environment. One possible pathway to address the evidence gap and entrenched 
biases is to analyze conference submissions. Conferences are an important part of academic culture and student conferences especially provide early-career scientists with an opportunity to showcase and discuss their ideas, projects, and fieldwork at a stage prior to publication. While not immune or without possible biases of their own, conference submissions may be less vulnerable to some of the issues in the peer-reviewed literature (e.g. positive-results publication bias, English language skills) and could identify the disconnect between on-the-ground research and the published literature. This information could help to utilize the full potential of the conservation research community.

In this study, we assessed the scope, data and methods of studies submitted for presentation at the Student Conference on Conservation Science (SCCS) in Cambridge, UK using a database of $>3000$ applications. To our knowledge, SCCS is the oldest dedicated student conservation conference. Over the 20 years it has been running, it has welcomed applications from bachelor, masters and $\mathrm{PhD}$ students. It has never had a thematic focus but instead encourages submissions from across the diverse disciplines of conservation science. It has consistently received applicants from around the world, in part thanks to its provision of bursaries to those from lower income countries.

We classified these applications to explore patterns and trends over time in what conservation students study, focusing on potential changes in framing, the types of studies conducted, the methods used, and the integration of data and ideas from the social sciences. We were particularly interested in understanding if the transition from conservation as a predominantly biological science to a more multidisciplinary one had changed the framing around the value of nature to people or the integration of the social sciences.

\section{Material and methods}

We included 3,487 submissions for oral presentations (i.e. poster submissions were excluded) at SCCSCambridge covering 15 individual years spanning the 18 years between 2002-2019. These are the years for which we had access to all the original conference submissions, not only accepted submissions, to ensure we captured the full scale of work undertaken and to avoid any selection bias by the conference organisers. The years 2000, 2001, 2004, 2005, and 2006 were excluded due to missing data. Ethics approval was obtained through the Human Biology Research Ethics Committee, School of Biological Sciences, University of Cambridge (ref no.: PRE.2018.068). Conference submissions were anonymized before being used to generate a database of submissions containing: 1) Row ID, 2) Nationality, 3) Country of residence, 4) Stage in career, 5) Talk title, and 6) Talk abstract. E-mails were sent to all applicants asking them to reply if they did not want to be included in the study. This led to the removal of seven submissions.

The data extraction protocol and guidelines outlining the information extracted from each submission were developed prior to reviewing the submissions (Table S1). The protocol was pilot tested on a subset 
121 of submissions $(\mathrm{n}=20)$ by a sub-group of reviewers and subsequently revised based on these experiences. Two workshops were conducted prior to the data extraction to explain and discuss the final protocol. In total, 25 of the paper's authors participated in the data extraction based on the information in the submissions database. The conference-submissions were assigned randomly among all 25 reviewers, with each reviewer extracting data from approximately 140 abstracts. The year of submission was removed to avoid biasing the data extraction.

\subsection{Data extraction}

For each submission (title and abstract), the reviewers extracted information on the applicant (nationality, country of residence, career stage) as well as on 25 elements pertaining to the research carried out by the student. The abstracts for 2002 and 2003 consisted of a title and an abstract with no formatting requirements. For subsequent years the abstract was divided into four parts: 1) What conservation problem or question does your talk address?, 2) What were the main research methods you used?, 3) What are your most important results?, and 4) What is the relevance of your results to conservation?. The 25 elements covered research locations (e.g. country, region); study type (i.e. field, laboratory, modelling, remote sensing); and scale of study (e.g. local, national, multi-country) (see Table S1 for the full list and definitions). Where possible, answers were assigned to predefined categories (e.g. realm of study: terrestrial, marine, freshwater, coastal, or multiple). In addition, reviewers used 'not sure' where the abstract did not allow a clear interpretation or 'not applicable' where a particular question was not relevant.

Where one or multiple species were studied, we recorded the broad taxon using 16 categories: algae, lichens, plants, fungi, arthropods, marine invertebrates, other invertebrates, fish, amphibians, reptiles, birds, mammals, other, multiple, not applicable, and not sure.

For each conference submission each reviewer assessed whether the study primarily addressed 'Pressure', 'State', or 'Response' following the PSR-framework of the Organisation for Economic Cooperation and Development (1993). For example, a study could examine the effect of protected areas (response) in reducing hunting (pressure) on numbers of lions (state). This was done based on an interpretation of the entire abstract. Where more than one category could apply, we used a hierarchical approach to assign a single category to each submission, where 'response' superseded 'pressure' which superseded 'state' - so the example above would be classed as a response study. The hierarchical approach was used to reflect the conceptual thinking behind the PSR-framework, that conservation is the human response to human pressures affecting the natural state of the world.

We extracted information on the extent to which human dimensions were included in the studies through two questions. The first addressed whether the submission mentioned conservation benefiting people and/or the importance of involving people in conservation decisions. It was not necessary for the study 
to be primarily framed around the value of nature to people, only that the role of, or relevance to, people was articulated. The second addressed whether the primary focus of the study was the value nature provides to people.

We assessed whether submissions recorded biological data (e.g. species, habitats, genetics or any other data derived from a biological system) and/or socio-economic data (e.g. livelihood issues, economy/finances, attitudes, human behavior, or human behavior change). Additionally, we recorded if the data was collected by the students themselves, or if the study included secondary data sources.

Finally, we recorded the methods for both biological (e.g. transects, camera-traps, remote sensing, interviews) and socio-economic data collection (e.g. interviews, questionnaires). For biological methods the original 20 categories (Table S1) were reduced to six: 1) field data, 2) genetic data, 3) internet/literature search, 4) audio and camera recordings, 5) remote sensing, and 6) other.

Following data extraction, 359 (11.1\%) submissions were selected for kappa analysis to test the interreviewer variability in data extraction. This was done by randomly selecting $10 \%$ of the conferencesubmissions of each reviewer to be re-reviewed by a different randomly selected reviewer. For the years 2002 and 2003 we assessed $20 \%$ of each year following the same procedure. Kappa analysis was conducted on all questions individually and on overall agreement. Based on this, questions with a Cohen's kappa score below 0.6 (weak agreement) were not included in the analysis (McHugh 2012). The average Cohen's kappa for all included questions was 0.78 (S.E. $=0.07, \min =0.64, \max =0.87$, Table S2). Only the identification of main threat (Cohen's kappa $=0.21)$ did not meet this criterion, potentially because the perception of threats in the field does not always align with the five main categories used here and adopted from The Intergovernmental Science-Policy Platform on Biodiversity and Ecosystem Services. The years 2002 and 2003 were assessed separately leading to the exclusion of the Pressure-State-Response questions for those years (Cohen's kappa $=0.40)$.

\subsection{Analysis}

Prior to calculations of proportions, all empty fields, 'not applicable', and 'not sure' were removed. Thus, the number of responses for each year varies across analyses. For questions where we assessed proportional changes over time, we used beta-regression to model the proportion as the dependent variable and year as a continuous independent variable. All analyses were carried out in R 3.5.1 ( $R$ Development Core Team 2019).

\section{Results}

\subsection{Geographical and taxonomic focus}

We assessed 3,245 submissions after removing 235 that had been submitted but did not contain an abstract and/or title. Over the 18-year period, the conference received applications from 128 countries; 
with the highest number of applicants, by nationality, from India $(n=454)$, United Kingdom $(n=312)$,

195 Kenya $(n=125)$, Nigeria $(n=121)$, or Nepal $(n=100)$. By region, Asia was the largest source of 196 applicants $(\mathrm{n}=992)$, followed by Africa $(\mathrm{n}=961)$, Europe $(\mathrm{n}=598)$ and Latin America $(\mathrm{n}=213)$

\section{7 (Table 1).}

198 Table 1. Proportion of abstracts across the six regions

\begin{tabular}{|l|r|r|r|r|r|}
\hline Region & Nationality & \multicolumn{1}{|l|}{ Residence } & Fieldwork & $\begin{array}{l}\text { \% studies } \\
\text { based on own } \\
\text { fieldwork }\end{array}$ & $\begin{array}{l}\text { l people } \\
\text { focused }\end{array}$ \\
\hline Africa & $961(34 \%)$ & $958(33 \%)$ & $1,016(41 \%)$ & $82 \%$ & $36 \%$ \\
\hline Asia & $992(33 \%)$ & $921(34 \%)$ & $949(39 \%)$ & $83 \%$ & $26 \%$ \\
\hline Europe & $598(21 \%)$ & $846(21 \%)$ & $216(9 \%)$ & $73 \%$ & $27 \%$ \\
\hline Latin America & $213(7 \%)$ & $166(7 \%)$ & $222(9 \%)$ & $70 \%$ & $32 \%$ \\
\hline North America & $86(3 \%)$ & $115(3 \%)$ & $16(<1 \%)$ & $66 \%$ & $49 \%$ \\
\hline Oceania & $41(1 \%)$ & $55(1 \%)$ & $38(2 \%)$ & $51 \%$ & $17 \%$ \\
\hline
\end{tabular}

Nationality, residence and fieldwork shows the percentage of submissions (after removing those that noted not applicable and not sure) from each region. \% fieldwork and \% people-focused shows the percentage of submissions, within each region that included fieldwork and a focus on people related values respectively. For the last two columns, submissions were assigned a region based on the nationality of the applicant. Because of different degrees of missing data in individual questions, the sums across columns are not the same.

Noticeably there were very few submissions from North America $(n=86)$ and Oceania $(n=41)$. No changes were observed over time in the proportion of applicants from different regions (Fig. S1) and only a few, and minor changes, at the country level (Fig. S2). India was the country where the most studies took place $(\mathrm{n}=435)$, followed by South Africa $(\mathrm{n}=114)$, Kenya $(\mathrm{n}=110)$, Nepal $(\mathrm{n}=101)$, and Madagascar $(\mathrm{n}=97)$. Many applicants from Europe $(64 \%)$ and North America $(81 \%)$ worked outside their own region, which was much less the case with students from other regions (Fig. 1).

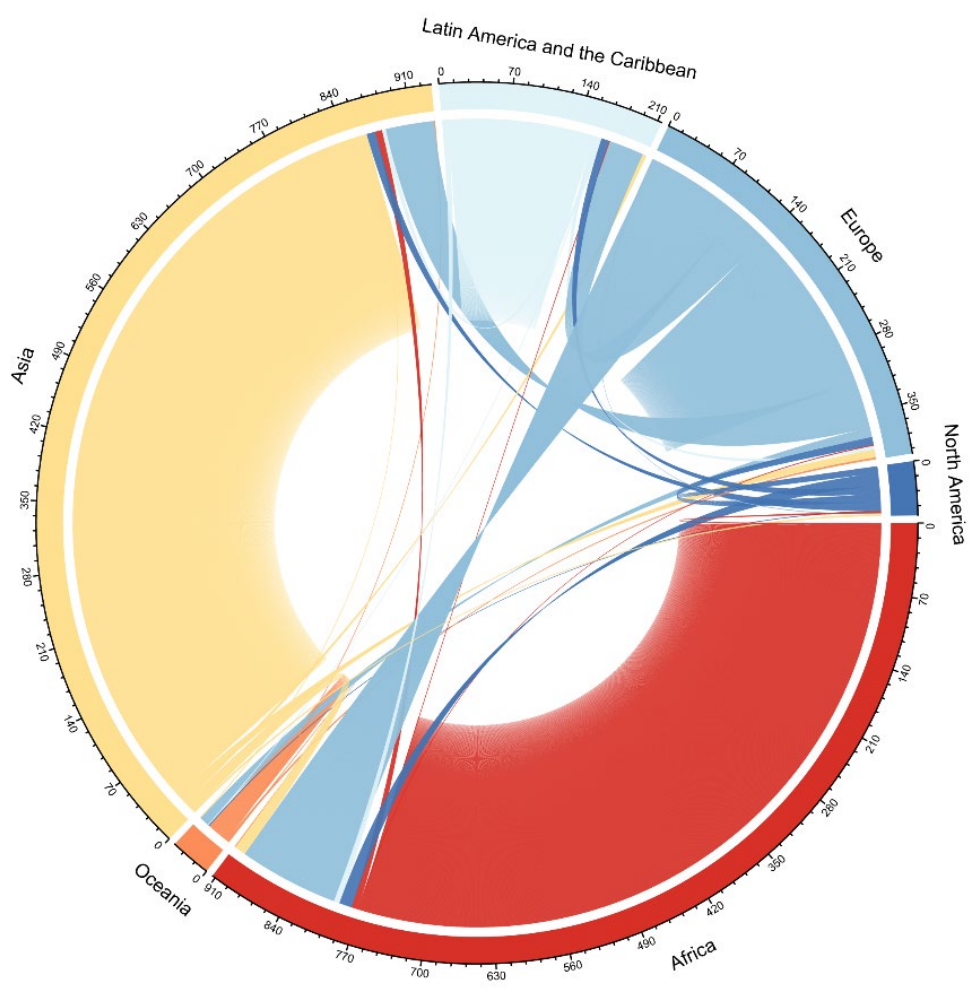

Figure 1. Diagram showing the number of SCCS applicants conducting fieldwork in different regions (the outer ring). The color of the inner (thicker) ring indicates the nationality, grouped by region, of the person conducting the research. The figure shows that there are more Europeans working in Africa, Asia, and Latin America and the Caribbean than there are people from those regions working in Europe. 
211 The vast majority of studies were terrestrial $(\mathrm{n}=2,393)$ followed by freshwater $(\mathrm{n}=225)$, marine $(\mathrm{n}=$ 212 177), multiple $(\mathrm{n}=119)$ and coastal $(\mathrm{n}=102)$. Across taxonomic groups, mammals were the most 213 studied $(n=875)$, followed by plants $(n=470)$, birds $(n=432)$, fish $(n=121)$ and arthropods $(n=89)$,

214 while potentially-important indicator groups, such as amphibians $(\mathrm{n}=58)$, fungi $(\mathrm{n}=10)$, and lichens $215(\mathrm{n}=2)$, were far less represented (Fig. 2).

216

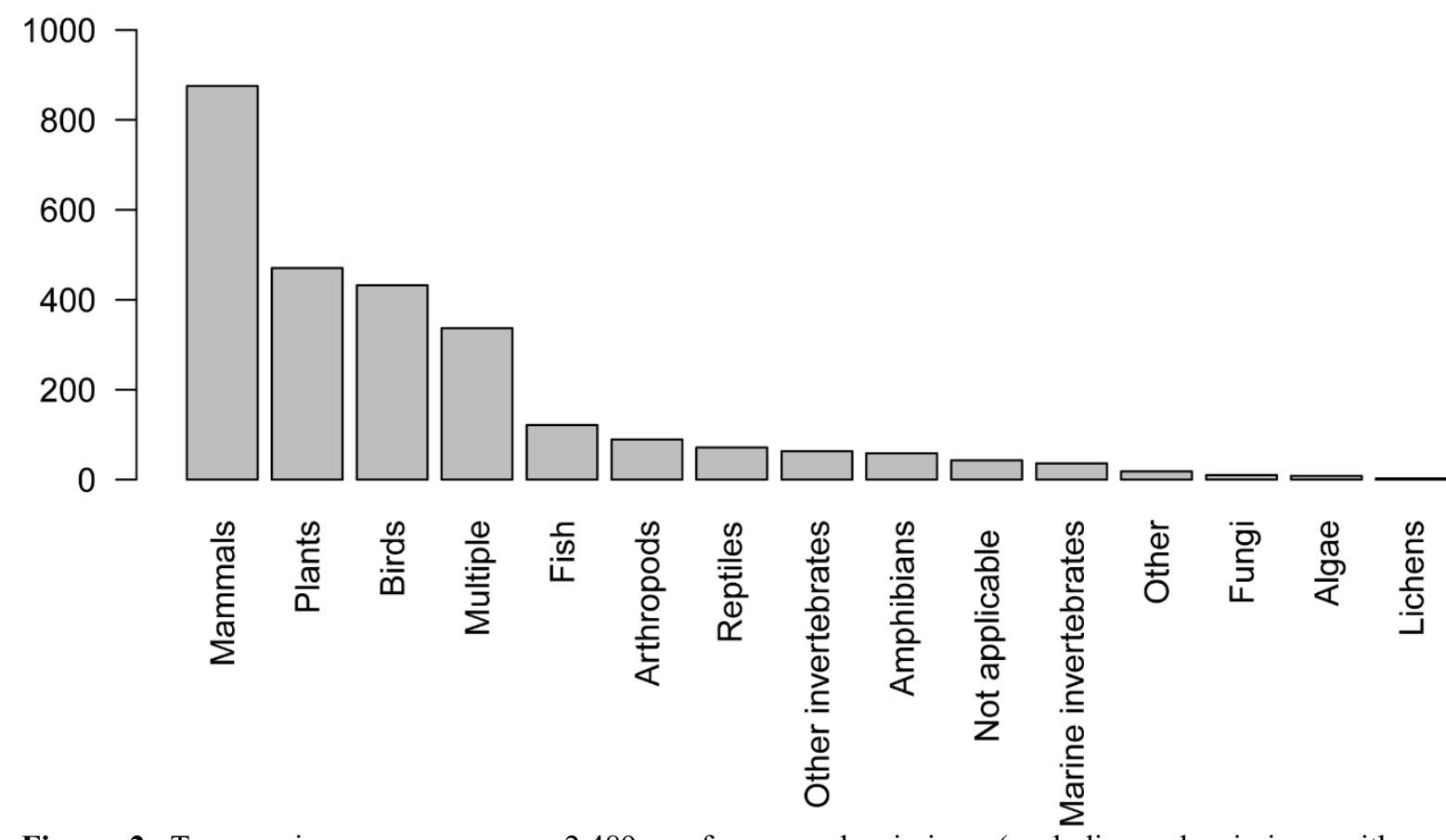

Figure 2. Taxonomic coverage across 2,489 conference sub-missions (excluding sub-missions with an ambiguous or no study taxon). Reviewers were explicitly asked to select the main species or higher taxonomic unit of interest. Where other species were described but were not the focus of the study, they have not been recorded.

\section{$217 \quad 3.2$ Framing}

218 On average, $38 \%(n=1,003)$ of all studies focused on the state of nature, investigating patterns of 219 biodiversity and processes, followed by $36 \%(\mathrm{n}=954)$ addressing pressure to biodiversity, and $26 \%(\mathrm{n}$ $=671$ ) addressing responses. No changes were observed between 2007 and 2019 in the proportions of state, pressure and response studies (Fig. 3a).

Of all the submissions, $31.3 \%(n=983)$ mentioned the importance of conservation benefiting people and/or the importance of involving people in conservation decisions, with no change observed over time. While remaining relatively low, in absolute terms $($ mean $=11.8 \%)$ the number of submissions with a primary focus on the value of nature to people increased significantly (z-value $=2.62, p=0.009$, $\mathrm{DF}=13)$ more than doubling from $2002($ estimate $=7.0 \%)$ to $2019($ estimate $=16.5 \%$; Fig. 3b). 


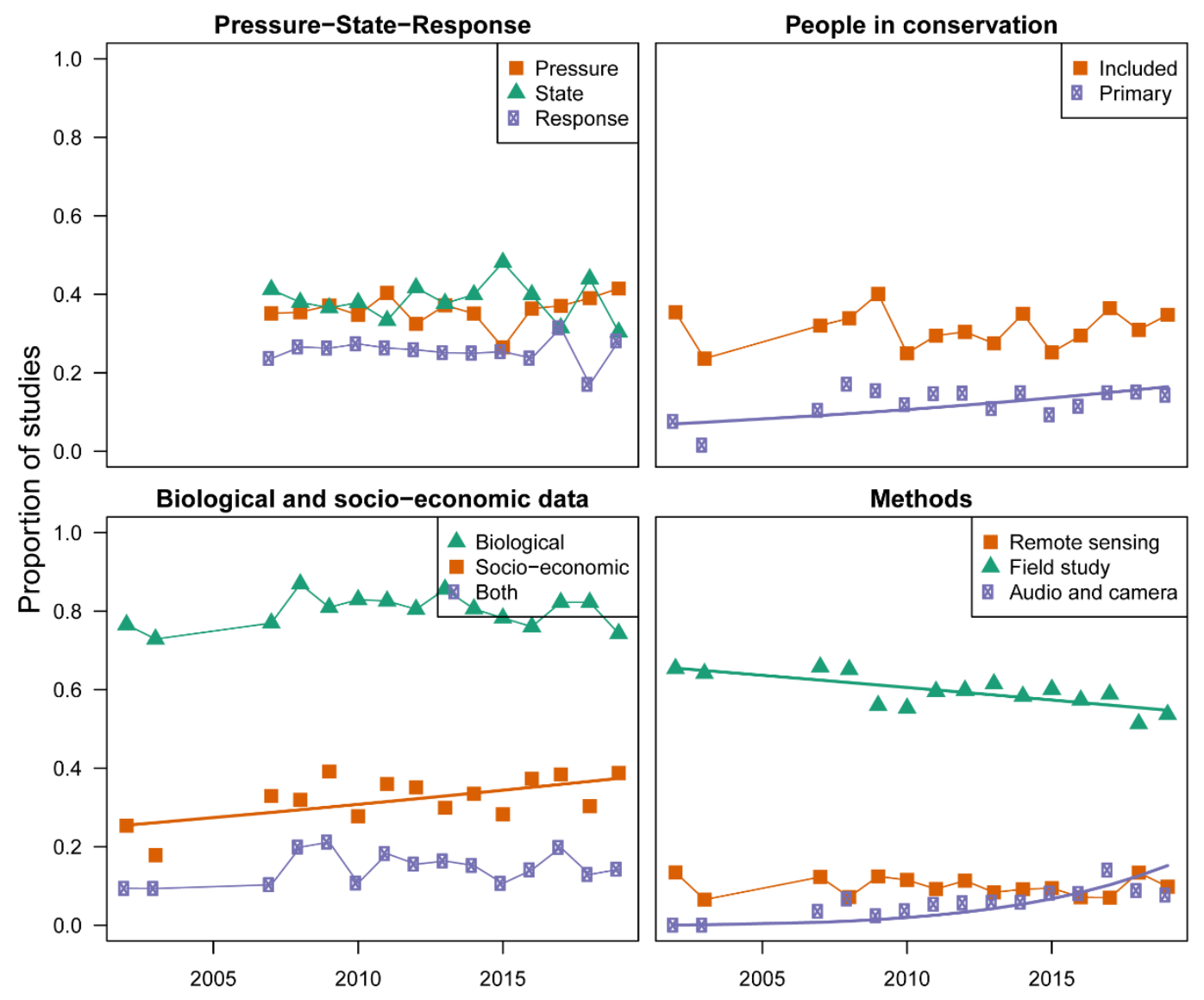

Figure 3. Change over time in the proportions of (a) studies that looked at pressure-state-responses, (b) studies that mentioned the importance of conservation to benefiting people and/or the importance of involving people in conservation decisions, or studies whose primary focus was to understand the values that nature provides to people, (c) studies that including biological data or socio-economic data, or both, and (d) studies using different methods. Studies that noted 'Not applicable', 'Not sure' or did not provide an answer for the questions involved were not included. Dots are connected where not significant relationship $(\mathrm{p} \geq 0.05)$ was identified while a regression line represents that a significant relationship $(\mathrm{p}<0.05)$ was identified

\subsection{Data and methods}

230 Most submissions $(80 \%, \mathrm{n}=2,442)$ contained biological data, while data on socio-economic aspects were less common $(33 \%, n=998)$. Only $15 \%(n=454)$ reported both biological and socio-economic data in the submissions. For biological data and the combination of biological and socio-economic data, the proportions showed no change over time. However, the proportion of submissions including socioeconomic data increased over time from $25.6 \%$ to $37.2 \%$ (estimate $=0.03, \mathrm{~S} . \mathrm{E}=0.01, \mathrm{p}=0.004, \mathrm{DF}=$ 13; Fig. 3c). Most of the data, both biological $(66 \%, n=2,001)$ and socio-economic $75 \%(n=852)$, were collected by the students themselves. Eighty percent $(n=2,457)$ of the submissions contained a field-collection element (Table 1) with 74\% $(n=2,090)$ of the submissions covering local-scale studies that looked at one or a few sites, and only $17 \%(n=475)$ of studies investigating patterns at national level, $7 \%(n=186)$ looking at multiple countries, and $2 \%(n=66)$ conducting global analyses.

The methods used to collect biological data remained relatively constant over time and were dominated by field-based approaches, such as transects, plots and trapping $(58.4 \%, \mathrm{n}=1,691)$. A decrease (from $65.5 \%$ in 2002 to $54.8 \%$ in 2019) was observed in the use of traditional field-based methods (estimate 

$=-0.026, \mathrm{~S} . \mathrm{E}=0.006, \mathrm{p}<0.001, \mathrm{DF}=13$ ), and there was an increase (from $0 \%$ in 2002 to $15.2 \%$ in 2019 ) in the use of audio and camera recordings (estimate $=0.21, \mathrm{~S} . \mathrm{E}=0.041, \mathrm{p}<0.001, \mathrm{DF}=13$ ). This suggests a change in approach toward more automated methods, rather than a decrease in fieldbased data-collection (Fig. 3d).

\section{Discussion}

Our results show that the majority of submissions to SCCS between 2002 and 2019, were based on primary biological data from local-scale field studies. These findings suggest a different trend to the concerns raised in previous research: that there is a decrease in the proportion of field-based studies in the peer-reviewed literature (Carmel et al. 2013; Ríos-Saldaña et al. 2018). Likewise, contrary to the dominance of researchers from wealthier countries found by reviews of published papers (Amano and Sutherland 2013), the majority of submissions to SCCS were from Asian and African nationals. These two continents were even more prominent when looking at the countries in which people collected data (Fig 1). For example, citizens from the UK represented the second largest group of applicants, but the UK ranked 15th as a location for fieldwork.

The discrepancy, in terms of type and location of studies, between the published literature and submissions to SCCS, highlights a potential barrier in the pathway from fieldwork to publication that warrants further exploration. It is possible that conferences allow participants to present more creative and less fully developed ideas that will be filtered out or modified once they get submitted to peerreviewed journals. Thus, conferences can play an important role in supporting and testing novel ideas that might be harder to get through a review process. It is possible that this explains the discrepancy between our findings, and studies of peer-reviewed papers that find a decrease in the proportion of fieldwork based studies. Thus, it may be that though the proportion of field-based research is not decreasing, field-based studies are being accepted less by journals. Furthermore, it suggests that the identified knowledge and data gaps in the published literature for the tropics (Christie et al. 2019; Collen et al. 2008; Mammides et al. 2016; Meijaard et al. 2015), may not only be driven by the lack of research effort and data-collection, but by publication bias. This is of particular concern given the significant biodiversity importance of tropical areas (Brooks et al. 2006; Myers et al. 2000).

There is an urgent need to improve the uptake of studies from the tropics in the peer-reviewed literature to ensure the availability of knowledge and data in conservation research and efforts. This will both directly benefit the conservation community and ensure a greater diversity in the people and views represented within conservation science. To achieve such improvements, it is important to support the data-collection-publication pipeline in areas currently underrepresented in the published literature. This may include reduced or waived publication fees (already applied by some journals), as well as language support for non-native English speakers, which is a major barrier in the publication process (Amano et al. 2016). In some cases, there might also a need for capacity building (Legg and Nagy 2006) and to 
assist people in scientific writing. For example, in a capacity-building program in Africa run by the Tropical Biological Association, a focus on how to write scientific articles resulted in 87 publications (Pers obs. R. Trevelyan).

While the peer-review process is foundational for the publication of scientific studies, it is not the only way to publish data. An increasing number of online data repositories allow for data sharing outside the traditional publication pathway. Similar to the role of GenBank (NCBI Resource Coordinators 2017) in molecular biology, such databases might help to publicize data currently unavailable in the public sphere. However, to be successful, this should be linked to transparent standards (Poisot et al. 2019), a formalized method of citing the data-collectors, and must be accompanied by the development of appropriate and fair crediting mechanisms for data collectors by institutions and funding bodies. Data can represent value, both monetary and cultural, thus where fieldwork is taking place outside the country of the institution, the access to data should be accompanied by benefit-sharing (Baker et al. 2019). If such mechanisms are not in place, data-sharing outside the peer-reviewed literature may not benefit data-collectors in the developing world but rather lead to exploitation of field efforts by other researchers.

Over the 18-year for which we had data, the number of submissions that focused on the value that nature provides to people increased. This corresponds with the emergence within the conservation community of a 'nature for people' framing (Mace 2014), which has profoundly influenced the strategies of some of the world's largest conservation organizations (e.g. Conservation International and The Nature Conservancy; Kareiva et al. 2014). However, this narrative has been criticized as western-dominated (Tallis and Lubchenco 2014) and as describing a polarization not actually found in the conservation community (Sandbrook et al. 2019). In this light, it is interesting that while we observed a significant trend over time, the proportion of SCCS submissions focused on the services and goods that nature provides to people remained low. Thus, our results suggest that while the emphasis on people is a component in conservation, it is by no means dominant. It is possible that our sample, with a majority from lower-income countries, might be less influenced by this trend in conservation than in higherincome regions. North America and Australia, which are among the largest contributors to peerreviewed journal articles in conservation science, were almost entirely absent in our sample (potentially related to the distance to Cambridge, $\mathrm{UK}$ ) while also being among the strongest proponents of a more people focused conservation narrative (Tallis and Lubchenco 2014).

The submissions we assessed support suggestions that conservation science is broadening (Teel et al. 2018) by revealing an increase over time in the use socio-economic data. However, the proportion remained relatively low across the 18 years. Additionally, the number of studies integrating both biological and socio-economic data did not increase, with only around $16 \%$ of studies combining 
318 biological and socio-economic data in the same study. This suggests that while conservation has become 319 increasingly multi-disciplinary, there is still considerable scope for further integration (also see 320 Guerrero et al. 2018). The call for integrating socio-economic perspectives into conservation research 321 is not new (e.g. Adams and McShane 1992), and it is increasingly recognized that both biological and 322 socio-economic perspectives are vital to conservation success (Martin et al. 2016). The continued 323 paucity of socio-economic considerations in conservation science that we observed highlights the need 324 to broaden the training of future conservation researchers. This requires university departments and faculties to foster integration and to break down silos between disciplines and departments.

The majority of studies focused on describing biological states or human pressures, while only $26 \%$ evaluated conservation interventions and solutions. Our results therefore mirror several papers that highlight the lack of studies assessing the impact of conservation responses (Geldmann et al. 2013; Schleicher 2018). While we recognize that an understanding and description of the state of nature and the pressures it faces provides a foundation for developing effective responses, the under-representation of studies assessing the impact of conservation efforts is concerning, given longstanding calls for increasing evidence on the effectiveness of conservation interventions (Pullin and Knight 2001; Sutherland et al. 2004). Assessing the impact of conservation responses is fundamental to improving their effectiveness (Balakrishna 1999; Ferraro 2009) as well as measuring progress towards achieving policy targets (Fisher et al. 2014). It is possible that the complexity of assessing conservation impact (Baylis et al. 2016) is limiting the number of such studies undertaken by students, who are often constrained by time and may lack the experience required to undertake complex impact assessments. Additionally, students attending conferences may wish to present earlier parts of their projects, even if this represents only a step towards the overall objective (i.e. submit the field stage if analysis isn't completed). However, it is vital that conservation science increasingly addresses this knowledge gap (Baylis et al. 2016; Miteva et al. 2012; Schleicher 2018) to better understand what works, when and why.

By following 18 years of submissions from the longest running student conservation conference, our study provides a unique temporal insight into the work undertaken by successive cohorts and earlycareer conservation scientists. In including all submissions to give a talk, our sample is not biased by the quality of submissions or by temporal shifts in the preferences of the selection committees but represents the full diversity of students applying for SCCS. Nevertheless, our sample might not represent the wider community as self-selection might exclude some from submitting. Conducting similar analysis of other student and/or conservation conferences where similar long-term data exists, would help to clarify these potential biases. As with published studies (Amano et al. 2016; Amano and Sutherland 2013), countries (often former British colonies) where it is more common to communicate 
a representative sample of all conservation studies. Moreover, the low proportion of marine studies indicates that SCCS has tended to attract a lower proportion of those working on marine conservation, perhaps due to the organizers having mostly terrestrial experience and networks. In general, conferences can exacerbate such geographical and topical biases related to the organizer's areas of interest and the location of the conference. This might also have influenced the submission to SCCS Cambridge and thus how well suited this sample is for comparing to the wider academic conservation literature.

The dominance of field studies from the tropics in the conference submissions might not reflect a dominance of field studies in general. Rather, it is possible that fieldwork in temperate zones is framed more as ecological research without a conservation focus. Nevertheless, our study suggests that there is an untapped resource in field studies and more tropical research being undertaken by students from tropical countries than is suggested by the published literature.

\section{Conclusion}

Based on our findings we see an urgent need to make data generated by tropical fieldworkers more widely available, and for increased efforts in examining the impact of conservation interventions. It is important that any initiative focus on developing the capacity of and provide agency for the people conducting the data-collection to help further their careers as independent researchers in their own right. Our results also highlight that conservation science still needs to further integrate disciplines outside biology. Only through combining understanding of both the natural world and human behaviour can we successfully tackle the great challenges facing Earth's biodiversity, without jeopardizing the sustainable livelihood of our own species.

\section{Acknowledgements}

We thank the all past participant of SCCS Cambridge who submitted an abstract to give a talk. The project was made possible through funding from: JG: EUs Horizon 2020 Marie Skłodowska-Curie program (No 676108) and VILLUM FONDEN (VKR023371), HA-P; National Council for Scientific and Technological Development (CNPq) (203407/2017-2), TA: The Australian Research Council Future Fellowship (FT180100354), The Grantham Foundation for the Protection of the Environment and The Kenneth Miller Trust, APC: the Natural Environment Research Council (NERC DTP [NE/L002507/1]), LC: Cambridge International Scholarship from the Cambridge Trust, FH: the Newton International Fellowship of the Royal Society, DM: the Australian Government, Endeavor Postgraduate Scholarhip, HM: Branco Weiss Fellowship Administered by the ETH Zürich and Drapers' Company Fellowship, Pembroke College BIS: the Natural Environment Research Council (NERC DTP [NE/L002507/1 and NE/S001395/1]) and the Royal Commission for the Exhibition of 1851 Research Fellowship, HW: Cambridge Trust Cambridge-Australia Poynton Scholarship and Cambridge Department of Zoology J. S. Gardiner Scholarship.

\section{Author statement:}

Conceptualization: JG; Methodology: JG with input from all co-authors; Data collection and curation: HPA, TA, HB, APC, LC, SCC, RC, IC, AD, TF, EEG, JG, FH, TK, DM, PAM, NM, HSM, CP, SOP, RR, KR, BIS, HW, TAW; Formal analysis: JG; Writing: JG with input from all co-authors 


\section{References}

Adams, J., McShane, T., 1992. The Myth of wild Africa: conservation without illusions. University of California Press, Berkeley, California, USA.

Amano, T., González-Varo, J.P., Sutherland, W.J., 2016. Languages Are Still a Major Barrier to Global Science. PLOS Biology 14, e2000933.

Amano, T., Sutherland, W.J., 2013. Four barriers to the global understanding of biodiversity conservation: wealth, language, geographical location and security. Proceedings of the Royal Society B: Biological Sciences 280.

Baker, K., Eichhorn, M.P., Griffiths, M., 2019. Decolonizing field ecology. Biotropica 51, 288-292.

Balakrishna, P., 1999. Biodiversity conservation and impact assessment. Current Science 76, 129-131.

Balmford, A., Cowling, R.M., 2006. Fusion or Failure? The Future of Conservation Biology. Conservation Biology 20, 692-695.

Baylis, K., Honey-Rosés, J., Börner, J., Corbera, E., Ezzine-de-Blas, D., Ferraro, P.J., Lapeyre, R., Persson, U.M., Pfaff, A., Wunder, S., 2016. Mainstreaming Impact Evaluation in Nature Conservation. Conservation Letters 9, 58-64.

Bennett, N.J., Roth, R., Klain, S.C., Chan, K., Christie, P., Clark, D.A., Cullman, G., Curran, D., Durbin, T.J., Epstein, G., Greenberg, A., Nelson, M.P., Sandlos, J., Stedman, R., Teel, T.L., Thomas, R., Veríssimo, D., Wyborn, C., 2017. Conservation social science: Understanding and integrating human dimensions to improve conservation. Biological Conservation 205, 93-108.

Brooks, T.M., Mittermeier, R.A., da Fonseca, G.A.B., Gerlach, J., Hoffmann, M., Lamoreux, J.F., Mittermeier, C.G., Pilgrim, J.D., Rodrigues, A.S.L., 2006. Global Biodiversity Conservation Priorities. Science 313, 58-61.

Carmel, Y., Kent, R., Bar-Massada, A., Blank, L., Liberzon, J., Nezer, O., Sapir, G., Federman, R., 2013. Trends in Ecological Research during the Last Three Decades - A Systematic Review. PLoS ONE 8, e59813.

Christie, A.P., Amano, T., Martin, P.A., Petrovan, S.O., Shackelford, G.E., Simmons, B.I., Smith, R.K., Williams, D.R., Wordley, C.F.R., Sutherland, W.J., 2019. The challenge of heterogeneous evidence in conservation. bioRxiv, 797639.

Clark, J.A., May, R.M., 2002. Taxonomic Bias in Conservation Research. Science 297, 191-192.

Collen, B., Ram, M., Zamin, T., McRae, L., 2008. The tropical biodiversity data gap: addressing disparity in global monitoring. Tropical Conservation Science 1, 75-88.

Ferraro, P.J., 2009. Counterfactual thinking and impact evaluation in environmental policy. New Directions for Evaluation 2009, 75-84.

Fisher, B., Balmford, A., Ferraro, P., J., Glew, L., Mascia, M., Naidoo, R., Ricketts, T.H., 2014. Moving Rio Forward and Avoiding 10 More Years with Little Evidence for Effective Conservation Policy. Conservation Biology 28, 880-882.

Geldmann, J., Barnes, M., Coad, L., Craigie, I.D., Hockings, M., Burgess, N.D., 2013. Effectiveness of terrestrial protected areas in maintaining biodiversity and reducing habitat loss, p. 61. Collaboration for Environmental Evidence, Bangor, United Kingdom.

Godet, L., Devictor, V., 2018. What Conservation Does. Trends in Ecology \& Evolution 33, 720-730.

Greenwald, N., Dellasala, D.A., Terborgh, J.W., 2013. Nothing New in Kareiva and Marvier. BioScience 63, 241241.

Guerrero, A.M., Bennett, N.J., Wilson, K.A., Carter, N., Gill, D., Mills, M., Ives, C.D., Selinske, M.J., Larrosa, C., Bekessy, S., Januchowski-Hartley, F.A., Travers, H., Wyborn, C.A., Nuno, A., 2018. Achieving the promise of integration in social-ecological research: a review and prospectus. Ecology and Society 23.

Kareiva, P., 2014. New Conservation: Setting the Record Straight and Finding Common Ground. Conservation Biology 28, 634-636.

Kareiva, P., Groves, C., Marvier, M., 2014. The evolving linkage between conservation science and practice at The Nature Conservancy. Journal of Applied Ecology 51, 1137-1147.

Kareiva, P., Marvier, M., 2012. What is conservation science? BioScience 62, 962-969.

Legg, C.J., Nagy, L., 2006. Why most conservation monitoring is, but need not be, a waste of time. Journal of Environmental Management 78, 194-199.

Mace, G.M., 2014. Whose conservation? Science 345, 1558-1560.

Mammides, C., Goodale, U.M., Corlett, R.T., Chen, J., Bawa, K.S., Hariya, H., Jarrad, F., Primack, R.B., Ewing, H., Xia, X., Goodale, E., 2016. Increasing geographic diversity in the international conservation literature: A stalled process? Biological Conservation 198, 78-83.

Martin, J.-L., Maris, V., Simberloff, D.S., 2016. The need to respect nature and its limits challenges society and conservation science. Proceedings of the National Academy of Sciences 113, 6105-6112.

Martin, L.J., Blossey, B., Ellis, E., 2012a. Mapping where ecologists work: biases in the global distribution of terrestrial ecological observations. Frontiers in Ecology and the Environment 10, 195-201.

Martin, T.G., Burgman, M.A., Fidler, F., Kuhnert, P.M., Low-Choy, S., McBride, M., Mengersen, K., 2012b. Eliciting Expert Knowledge in Conservation Science

Obtención de Conocimiento de Expertos en Ciencia de la Conservación. Conservation Biology 26, 29-38.

McHugh, M.L., 2012. Interrater reliability: the kappa statistic. Biochemia medica 22, 276-282. 
Meijaard, E., Cardillo, M., Meijaard, E.M., Possingham, H.P., 2015. Geographic bias in citation rates of conservation research. Conservation Biology 29, 920-925.

Meine, C., Soulé, M., Noss, R.F., 2006. “A Mission-Driven Discipline”: the Growth of Conservation Biology. Conservation Biology 20, 631-651.

Miteva, D.A., Pattanayak, S.K., Ferraro, P.J., 2012. Evaluation of biodiversity policy instruments: what works and what doesn't? Oxford Review of Economic Policy 28, 69-92.

Myers, N., Mittermeier, R.A., Mittermeier, C.G., da Fonseca, G.A.B., Kent, J., 2000. Biodiversity hotspots for conservation priorities. Nature 403, 853-858.

NCBI Resource Coordinators, 2017. Database resources of the National Center for Biotechnology Information. Nucleic Acids Research 46, D8-D13.

Noss, R., Nash, R., Paquet, P., Soule, M., 2013. Humanity's Domination of Nature is Part of the Problem: A Response to Kareiva and Marvier. BioScience 63, 241-242.

Organisation for Economic Co-operation and Development, 1993. OECD core set of indicators for environmental performance reviews. OECD, Paris, France.

Poisot, T., Bruneau, A., Gonzalez, A., Gravel, D., Peres-Neto, P., 2019. Ecological Data Should Not Be So Hard to Find and Reuse. Trends in Ecology \& Evolution 34, 494-496.

Pullin, A.S., Knight, T.M., 2001. Effectiveness in conservation practice: Pointers from medicine and public health. Conservation Biology 15, 50-54.

R Development Core Team, 2019. R: A language and environment for statistical computing. R Foundation for Statistical Computing.

Ríos-Saldaña, C.A., Delibes-Mateos, M., Ferreira, C.C., 2018. Are fieldwork studies being relegated to second place in conservation science? Global Ecology and Conservation 14, e00389.

Sandbrook, C., Fisher, J.A., Holmes, G., Luque-Lora, R., Keane, A., 2019. The global conservation movement is diverse but not divided. Nature Sustainability 2, 316-323.

Schleicher, J., 2018. The environmental and social impacts of protected areas and conservation concessions in South America. Current Opinion in Environmental Sustainability 32, 1-8.

Soule, M., 2013. The "New Conservation". Conservation Biology 27, 895-897.

Soulé, M.E., 1985. What Is Conservation Biology? BioScience 35, 727-734.

Sutherland, W.J., Pullin, A.S., Dolman, P.M., Knight, T.M., 2004. The need for evidence-based conservation. Trends in Ecology \& Evolution 19, 305-308.

Tallis, H., Lubchenco, J., 2014. Working together: a call for inclusive conservation. Nature 515, 27-28.

Teel, T.L., Anderson, C.B., Burgman, M.A., Cinner, J., Clark, D., Estévez, R.A., Jones, J.P.G., McClanahan, T.R., Reed, M.S., Sandbrook, C., St. John, F.A.V., 2018. Publishing social science research in Conservation Biology to move beyond biology. Conservation Biology 32, 6-8.

Tewksbury, J.J., Anderson, J.G.T., Bakker, J.D., Billo, T.J., Dunwiddie, P.W., Groom, M.J., Hampton, S.E., Herman, S.G., Levey, D.J., Machnicki, N.J., del Rio, C.M., Power, M.E., Rowell, K., Salomon, A.K., Stacey, L., Trombulak, S.C., Wheeler, T.A., 2014. Natural History's Place in Science and Society. BioScience 64, 300-310.

Wilson, E.O., 2017. Biodiversity research requires more boots on the ground. Nature Ecology \& Evolution 1, 1590-1591. 